\title{
Web Developer Knowledge and Skills 2014
}

\author{
Janos Fustos, Gerard Morris, and Wayne Haga
}

\begin{abstract}
The authors collected data regarding the current demand for web developers, the education level requested, and the specific skills requested over a number of months on Dice.com. The requested skills were tabulated, categorized, and totals for both the categories and individual skills were computed. The key categories and specific skills are enumerated and the results show that the web development field requires an incredibly diverse set of knowledge and skills.
\end{abstract}

Index Terms-Web developer, job requirement, web programming, web scripting.

\section{Role AND PRofILE OF WEB DEVELOPERS}

Defining the role of web developer is complicated by the existence of related positions such as web designer and web master, plus an overlapping of roles in certain organizations. For example, a survey of 208 developers conducted over 24 countries found that a significant number of respondents classified themselves as "half-designer/half-developer [1]. Fox states there are different roles such a person could play and this could depend on the company [2]. Wikipedia defines the role as "a programmer who specializes in, or is specifically engaged in, the development of World Wide Web applications, or distributed network applications that are run over HTTP from a web server to a web browser" [3]. The Occupational Outlook Handbook published by United States Department of Labor's Bureau of Labor Statistics indicates what web developers do: "Web developers design and create websites. They are responsible for the look of the site. They are also responsible for the site's technical aspects, such as performance and capacity, which are measures of a website's speed and how much traffic the site can handle. They also may create content for the site" [4]. The handbook then goes into detail and mentions coding in HTML or XML, integrating graphics, audio, and video, and working with graphics and other designers [4].

Norrie found that $39 \%$ of web developers were between the ages of $20-30$ and $67 \%$ had five or more years of experience [1]. Approximately 25\% were self-employed in 2012 [4]. Lennon notes that "Learners are increasingly members of mixed generation, mixed ability class groups" [5].

\section{JOB OUTLOOK FOR WEB DEVELOPERS}

The Occupational Outlook Handbook indicates a strong outlook for these positions: "Employment of web developers is projected to grow $20 \%$ from 2012 to 2022 , faster than the

Manuscript received December 12, 2014; revised February 4, 2015.

The authors are with the Department of Computer Information Systems, Metropolitan State University of Denver, Denver, CO 80217 USA (e-mail: fustos@msudenver.edu,morrisgj@msudenver.edu, haga@msudenver.edu). average for all occupations. Demand will be driven by the growing popularity of mobile devices and ecommerce" with a median pay of $\$ 62,500$ in 2012. This contrasts with the projected increase for all occupations of $11 \%$ [4].

\section{A. Education and Certifications}

A survey of web developers in academic libraries indicated a range of education from associate's degree (35.5\%) to doctorates (9\%) [6]. Norrie's 2014 study found that a significant number had no formal qualification in computer science (numbers varied between $65 \%$ for those using Word Press to $52 \%$ for those using a content management system (CMS) [1]. A suggested curriculum by Xiaohui and Zhimin breaks the material down by web positions such as webpage art designer, webpage designer, and dynamic web developer. They suggested coursework in PHP and database for the web developer role [7]. Lennon suggests that for"... young learners requirements for mobility and ease of egress has placed the focus on short learning sprints supported via learning nuggets" [5].

Certifications such as the Microsoft Certified Solutions Developer (MCSD): Web Applications - Solutions Developer are available to supplement formal education [8]. The certification covers material such as HTML5, CSS3, ASP.NET, and Azure. The top five certifications for 2015 include MCSD as well as Zend Certified Engineer PHP 5.5 and W3Schools Web Certifications: HTML, CSS, JavaScript\& More [9].The level of breadth and detail in the web developer field is also evidenced by such specialized books as Web Developer's Cookbook which includes more than 300 ready-made PHP, JavaScript, and Cascading Style Sheets (CSS) recipes [10].

\section{B. Web Developer Skills}

The range of skills covers many different fields of study. Characteristics of web developers include creativity, meaning construction, and abstract thinking and problem solving [11]. These characteristics indicate that these developers have more than technical expertise in their toolbox. Skill categories include languages, both traditional and scripting, operating systems, database, protocols, servers, and frameworks [12]. Fox in his 2013 book also listsa broad range of skills. It adds languages like Ruby and Python to the skill set, plus notes that an understanding of networks, bandwidth, caching, and proxy servers help the web developer "build a more efficient and easier to download website" [2].

Content Management System (CMS) themes design is a desirable skill in web development [13]. CMS customizations and platforms also appear in Stansberry's "10 Most Sought-after Skills in Web Development," along with framework knowledge, widget development, PSD to XHTML services, Facebook and iPhone applications, and Flash and Action Script knowledge [14]. Gyanwali in 2012 listed the 
same skills as being the most sought-after [15].

Other skills come in to play more often today than in the past due to changes in technology, for example mobile application development. Charl and lists a required skill set for nine mobile operating systems (OS), including iOS, Symbian, Windows Mobile, Google Android, and Samsung Bada. Skills required varied by OS with Android requiring Java (Harmony flavored, Dalvik VM), Apple iOS listing C and Objective $\mathrm{C}$, and Symbian requiring $\mathrm{C}, \mathrm{C}++$, Python, HyperText Markup Language (HTML)/CSS/JS [16].

Another area that poses new challenges for web developers is accessibility requirements such as Web Content Accessibility Guidelines (WCAG) and WCAG 2.0. According to W3C, WCAG 2.0 "is a stable, referenceable technical standard. It has 12 guidelines that are organized under 4 principles: perceivable, operable, understandable, and robust. For each guideline, there are testable success criteria, which are at three levels: A, AA, and AAA" [17]. A survey of 49 IBM web developers highlighted two concerns in relation to accessibility: "barriers to the developers designing accessible Web-based products, and what value they felt specific features in an 'accessibility' tool might have. They found designing for accessibility difficult, but more surprisingly, they found using the test tools and finding technology work-arounds equally hard" [18].

In summary, a survey of the literature reveals an incredibly wide and deep range of skills for web developers. In addition, the knowledge and skills are not just confined to the technical fields of study as the accessibility standards such as WCAG show.

\section{Methodology}

A search for jobs with "Web Developer" in the job title was performed at Dice.com. The search was performed for jobs listed in all 50 states. The job ads were collected over a contiguous period from August to September 2014. A total of 1,204 positions were included in the study. Percentages of skills requested were calculated based on the number of jobs that actually requested one or more specific skills $(N=1,204)$. The technical skills required were noted and tallied. Skills requested were recorded regardless of whether the skill was required or just preferred.

\section{RESULTS}

Table I summarizes the number and percentage for each category where at least one of the skills was requested and/or required.

The most required/requested skill was client side scripting (85.4\% requested one or more scripting languages). One or more skills in server side scripting $(61.7 \%)$, JavaScript libraries $(60.5 \%)$, programming languages $(55.5 \%)$ and database technologies $(52.3 \%)$ were all required in more than $50 \%$ of the ads.

Table II identifies the requested/required skills for application servers. Experience with one or more application servers were only listed in $6.7 \%$ of the ads, with Tomcat $(2.6 \%)$ and JBoss $(2.2 \%)$ being the most common.
TABLE I: SKILL AREAS REQUESTED $(N=1204)$

\begin{tabular}{|l|c|c|}
\hline \hline Category & $n$ & $\%$ \\
\hline Application Servers & 81 & $6.7 \%$ \\
\hline Database Servers & 476 & $39.5 \%$ \\
\hline Web Servers & 156 & $7.8 \%$ \\
\hline Operating Systems & 301 & $25.0 \%$ \\
\hline Programming languages & 668 & $55.5 \%$ \\
\hline Client side scripting & 1028 & $85.4 \%$ \\
\hline Server side scripting & 743 & $61.7 \%$ \\
\hline JavaScript Libraries & 728 & $60.5 \%$ \\
\hline Database Technologies & 630 & $52.3 \%$ \\
\hline \hline
\end{tabular}

Note: Percentages of individual skills do not add up to the percentage given in Table I because multiple requests for skills within a category have been eliminated. For example if both Tomcat and JBoss were mentioned in the same advertisement, it was only counted as one request in the summary of the application server category. Further, skills with a very low count (less than $1 \%$ ) were included in the summary count, but dropped from being listed in tables.

TABLE II: APPLICATION SERVERS (REQUESTED IN 6.7\% OF ADS)

\begin{tabular}{|l|c|c|}
\hline \hline Application Server & $n$ & $\%$ \\
\hline Tomcat & 31 & $2.6 \%$ \\
\hline JBoss & 27 & $2.2 \%$ \\
\hline Coldfusion & 17 & $1.4 \%$ \\
\hline Jenkins & 16 & $1.3 \%$ \\
\hline
\end{tabular}

The skills called for in the area of Database Servers is shown in Table III. MySQL (18.4\%) was number one, followed closely by SQL Server (17.4\%) and then Oracle $(10.0 \%)$

TABLE III: DATABASE SERVERS (REQUESTED IN 39.5\% OF ADS)

\begin{tabular}{|l|c|c|}
\hline Database Server & $n$ & $\%$ \\
\hline MySQL & 222 & $18.4 \%$ \\
\hline SQL server & 210 & $17.4 \%$ \\
\hline Oracle & 120 & $10.0 \%$ \\
\hline MS-SQL/SSIS/SSRS & 37 & $3.1 \%$ \\
\hline
\end{tabular}

Table IV identifies the requests for Web Servers. Apache $(4.1 \%)$ and IIS $(3.0 \%)$ were the top two.

TABLE IV: WEB SERVERS (REQUESTED IN 7.8\% OF ADS)

\begin{tabular}{|l|c|c|}
\hline Web Server & $n$ & $\%$ \\
\hline Apache & 83 & $4.1 \%$ \\
\hline Internet Information Service (IIS) & 60 & $3.0 \%$ \\
\hline Web sphere & 21 & $1.0 \%$ \\
\hline Nginx & 9 & $0.4 \%$ \\
\hline \hline
\end{tabular}

Experience with Linux was requested for $10.6 \%$ of jobs followed by $9.9 \%$ for Windows. The mobile operating systems (Android and iOS) were each mentioned in about $6 \%$ 
of the ads, reflecting the emergence and growing numbers of mobile devices today. Table $\mathrm{V}$ summarizes the count and percentage for operating systems.

TABLE V: OPERATING SYSTEMS (REQUESTED IN 25\% OF ADS)

\begin{tabular}{|l|c|c|}
\hline \hline Operating system & $n$ & $\%$ \\
\hline Linux & 128 & $10.6 \%$ \\
\hline Windows & 119 & $9.9 \%$ \\
\hline Android & 71 & $5.9 \%$ \\
\hline iOS & 70 & $5.8 \%$ \\
\hline UNIX & 53 & $4.4 \%$ \\
\hline Windows server & 21 & $1.7 \%$ \\
\hline OS X & 16 & $1.3 \%$ \\
\hline \hline
\end{tabular}

Table VI shows the programming languages requested. Java $(32.9 \%)$ was the most requested language, followed by C\# (25.5\%). Both scored significantly higher than the other requested languages.

TABLE VI: PROGRAMMING LANGUAGES (REQUESTED IN 55.5\% OF ADS)

\begin{tabular}{|l|c|c|}
\hline \hline Language & $n$ & $\%$ \\
\hline Java & 396 & $32.9 \%$ \\
\hline C\# & 307 & $25.5 \%$ \\
\hline Visual Basic (VB) & 88 & $7.3 \%$ \\
\hline VB.NET & 55 & $4.6 \%$ \\
\hline C++ & 46 & $3.8 \%$ \\
\hline \hline
\end{tabular}

Table VII summarizes the specific skills requested in client side scripting. JavaScript was the most requested skill (77.1\%), followed by CSS $(61 \%)$.

TABLE VII: CLIENT SIDE SCRIPTING (REQUESTED IN 85.4\% OF ADS)

\begin{tabular}{|l|c|c|}
\hline \hline Language & $n$ & $\%$ \\
\hline JavaScript & 928 & $77.1 \%$ \\
\hline CSS & 735 & $61.0 \%$ \\
\hline AJAX & 309 & $25.7 \%$ \\
\hline CSS3 & 259 & $21.5 \%$ \\
\hline \hline
\end{tabular}

Table VIII summarizes the specific skills requested for server side scripting. Experience with PHP was the most requested skill (28.2\%) followed by ASP/ASP.NET (24.6\%)

TABLE VIII: SERVER SIDE SCRIPTING (REQUESTED IN 61.7\% OF ADS)

\begin{tabular}{|l|c|c|}
\hline Language & $n$ & $\%$ \\
\hline PHP & 339 & $28.2 \%$ \\
\hline ASP/ASP.NET & 296 & $24.6 \%$ \\
\hline Python & 103 & $8.6 \%$ \\
\hline JSP & 95 & $7.9 \%$ \\
\hline Ruby & 85 & $7.1 \%$ \\
\hline Perl & 52 & $4.3 \%$ \\
\hline
\end{tabular}

Experience with one or more JavaScript libraries was asked for in $60.5 \%$ of the ads. The most popular libraries are listed in Table IX. jQuery was by far the most common (50.1\%). These numbers point to an ever more specialized field and the deep skill set required of web developers today.

TABLE IX: JAVA SCRIPT LIBRARY (REQUESTED IN 60.5\% OF ADS)

\begin{tabular}{|l|c|c|}
\hline Library & $n$ & $\%$ \\
\hline jQuery & 603 & $50.1 \%$ \\
\hline angular & 146 & $12.1 \%$ \\
\hline bootstrap & 140 & $11.6 \%$ \\
\hline backbone & 123 & $10.2 \%$ \\
\hline node & 103 & $8.6 \%$ \\
\hline require & 61 & $5.1 \%$ \\
\hline ember & 45 & $3.7 \%$ \\
\hline knockout & 44 & $3.7 \%$ \\
\hline dojo & 30 & $2.5 \%$ \\
\hline d3 & 22 & $1.8 \%$ \\
\hline ext & 21 & $1.7 \%$ \\
\hline underscore & 21 & $1.7 \%$ \\
\hline
\end{tabular}

Table $\mathrm{X}$ summarizes the database technologies most in demand. SQL (39.6\%) and XML (22.8\%) were by far the most requested skills.

TABLE X: DATABASE TECHNOLOGIES (REQUESTED IN $52.3 \%$ OF ADS)
\begin{tabular}{|l|c|c|}
\hline Technology & $n$ & $\%$ \\
\hline SQL & 477 & $39.6 \%$ \\
\hline XML & 275 & $22.8 \%$ \\
\hline MongoDB & 37 & $3.1 \%$ \\
\hline JDBC & 20 & $1.7 \%$ \\
\hline ADO & 16 & $1.3 \%$ \\
\hline ODBC & 8 & $0.7 \%$ \\
\hline \hline
\end{tabular}

Table XI summarizes the educational level employers were looking for. Most indicated a computer science degree or closely related field was preferred. Only about a third of the job advertisements included a reference to a specific level of formal education. Most of them preferred a bachelor level degree $(28.6 \%)$. It was a big surprise that only twelve $(1 \%)$ advertisements mentioned certificates. These numbers underline even more that experience and not so much education is what hiring companies are ready to pay for. Lennon's comment that "Learners are increasingly members of mixed generation, mixed ability class groups" could imply that there is no method of education suited to the whole group and may explain some of the low numbers for formal education.

TABLE XI: LEVEL OF EDUCATION (REQUESTED IN 34.5\% OF ADS)

\begin{tabular}{|l|c|c|}
\hline Level of Education & $n$ & $\%$ \\
\hline Associates & 14 & $1.2 \%$ \\
\hline Bachelors & 344 & $28.6 \%$ \\
\hline Masters & 137 & $11.4 \%$ \\
\hline Ph.D. & 3 & $0.2 \%$ \\
\hline
\end{tabular}


Table XII summarizes the experience requests. Data shows that many companies want to bring in experienced professionals who have several years of practice in the field. The table also shows the potential applicants need to have previous experience to be considered for Web developer jobs. This emphasizes the importance of encouraging students to seek internships and get work experience as early as possible.

TABLE XII: EXPERIENCE (REQUESTED IN 46.7\% OF ADS)

\begin{tabular}{|c|c|c|}
\hline Experience & $n$ & $\%$ \\
\hline 1 year or more & 69 & $5.7 \%$ \\
\hline 1 & 33 & \\
\hline $1-2$ & 20 & \\
\hline $1-3$ & 16 & \\
\hline 2 years or more & 115 & $9.6 \%$ \\
\hline 2 & 59 & \\
\hline $2-3$ & 22 & \\
\hline $2-4$ & 17 & \\
\hline $2-5$ & 17 & \\
\hline 3 years or more & 146 & $12.1 \%$ \\
\hline 3 & 36 & \\
\hline $3-4$ & 4 & \\
\hline $3-5$ & 17 & \\
\hline $3-6$ & 6 & \\
\hline $3-7$ & 1 & \\
\hline 4 years or more & 44 & $3.7 \%$ \\
\hline 4 & 25 & \\
\hline $4-5$ & 9 & \\
\hline $4-6$ & 10 & \\
\hline $5+$ years & 188 & $15.6 \%$ \\
\hline
\end{tabular}

In addition to the aforementioned categories in Table I-Table XII, other general terms and specific skills appeared in the job postings albeit in smaller numbers. In terms of general themes, testing environments in total showed up in four percent of the postings with Jasmine and JUnit being the most requested. Testing in general was mentioned in $27.0 \%$ of ads. Agile development was requested in $22.9 \%$ of ads, the user interface in $13.6 \%$, and security in $11.0 \%$.

Specific technologies other than those in tables I-X include HTML (60.0\%), HTML5 (33.1\%), the architecture constraint system Representational State Transfer (REST) (10.9\%), CMS (9.3\%) and Word Press (8.3\%). In addition, protocols such as HTTP $(8.1 \%)$ and Simple Object Access Protocol (SOAP) $(6.8 \%)$ were also requested. Git, the version control system for software development, was listed in $11.1 \%$ of job postings. Other version control systems together added up to 13.0\%. Graphics editors such as Adobe Photoshop (10.1\%) and Adobe Illustrator (4.5\%) also scored high in the list of desired skills.

\section{SUMMARY AND CONCLUSION}

The 1,204 job postings for web developer on Dice.com included a varied set of knowledge and skills. While it is true that there is a breath of requested items from general issues such as security, testing, compliance systems, etc. to specific technical elements, the most requested items were specific skills in the areas of scripting, programming, and database.
Both client-side and server-side scripting scored very high with client-side scripting the most requested category. In this category JavaScript and CSS were the big winners. It is interesting to note that the web server category was only requested in $7.8 \%$ of postings. Apache at $4.1 \%$ was the most requested in this category. It seems to indicate that today's world of web development has got extremely specialized as indicated by the high scores for specific skills such as JavaScript coupled with JavaScript libraries (60.5\%), and CSS. Requests for graphics editors such as Photoshop show the overlap in some companies for the roles of webpage art designer and web developer.

The high percentages for the database categories, database technologies $(52.3 \%)$ and database servers $(39.5 \%)$ show the level of sophistication in web systems today. In the early days of the web, independent web servers were common. Today a web server is usually an access point to a database server in systems such as eCommerce.

The low percentage for forms of formal education and the very low number of ads (12) requesting certification is surprising. This could reflect the fact that many web developers are self-taught and started out as independent developers. This ties in with the Occupational Outlook Handbook statement that $25 \%$ of web developers were self-employed in 2012 [4].

\section{REFERENCES}

[1] M. Norrie, L. D. Geronimo, A. Murolo, and M. Nebeling, "The forgotten many? A survey of modern web development practices," Web Engineering, Lecture Notes in Computer Science, vol. 8541, pp. 290-307, 2014.

[2] R. Fox, Information Technology: An Introduction for Today's Digital World, 1st ed., Chapman and Hall/CRC, ch. 16, p. 488, 2013.

[3] Web Developer. (November 2, 2014). [Online]. Available: http://en.wikipedia.org/wiki/Web_developer

[4] Web Developers. (January 8, 2014). U.S. Bureau of Labor Statistic Occupational Outlook. [Online]. Available: http://www.bls.gov/ooh/computer-and-information-technology/web-d evelopers.htm

[5] R. Lennon, "Educating tomorrows web systems developers," in Proc. 14th IEEE International Symposium on Web Systems Evolution, Trento, Sept. 2012.

[6] R. Connell, "Survey of web developers in academic libraries," The Journal of Academic Librarianship, vol. 34, no. 2, pp. 121-129, March 2008.

[7] G. Xiaohui, and Z. Zhimin, "Construction of curriculum system on webpage design and website development in higher vocational colleges," in Proc. 6th International Conference on Computer Science \& Education (ICCSE 2011), pp. 657-659, Singapore, August 3-5, 2011.

[8] Microsoft.com. (2014). MCSD: Web Applications - Solutions Developer. $\quad$ [Online]. Available: https://www.microsoft.com/learning/en-us/mcsd-web-apps-certificati on.aspx

[9] E. Tittel and M. Kyle. (November 1, 2014). Best Web Certifications for 2015. [Online]. Available: http://www.tomsitpro.com/articles/web-certifications, 2-423.html

[10] R. Nixon, Web Developer's Cookbook, 1st ed., McGraw-Hill Osborne Media, 2012.

[11] F. Deek, N. Coppola, N. Elliot, and N. O’Daniel, "Cognitive characteristics of web developers: Creativity, meaning construction, \& problem solving," Web Net Journal, vol. 2, no. 2, pp. 36-50, April-June 2000.

[12] P. Bartlett, The Computer Science Resumes and Job-Finding Guide, Barron's Educational Series, 2005, ch. 3, pp. 42-43

[13] J. Sun, Q. Cai, and Y. Li, "Discussion on one sought-after skill in web development: CMS themes design," Advances in Electronic Commerce, Web Application and Communication, vol. 1, pp. 247-252, 2012. 
[14] G. Stansberry. (2008). 10 Most sought-after skills in web development. [Online]. Available: http://code.tutsplus.com/articles/10-most-sought-after-skills-in-web-d evelopment--net- 1265

[15] N. Gyanwali. (2012). What are the most sought after web development skills? [Online].

Available: http://www.nirmal.com.np/home/what-are-the-most-sought-after-web -development-skills-australia.html

[16] A. Charland and B. Leroux, "Mobile application development: Web vs. native," Communications of the ACM, vol. 54, no. 5, pp. 49-53, May 2011

[17] W3C. (October 2, 2012). Web content accessibility guidelines (WCAG) overview. [Online]. Available: http://www.w3.org/WAI/intro/wcag

[18] S. Trewin, B. Cragun, C. Swart, J. Brezin, and J. Richards, "Accessibility challenges and tool features: An IBM web developer perspective," in Proc. the 2010 International Cross Disciplinary Conference on Web Accessibility (W4A), Raleigh, NC, USA, April 26-27, 2010.

János Füstös is a professor of computer information systems at Metropolitan State University of Denver. His doctoral degree is in engineering management from the University of Veszprem, Hungary. He has taught a wide variety of information systems courses over the last 25 years, including courses in business computing, web site administration, and information systems security. His current research interests include web based cloud solutions, security topics, and accreditation.

Gerard Morris is a professor of computer information systems at Metropolitan State University of Denver. He has a Ph.D. in organic chemistry from University College Galway, Ireland (1981) and an MBA with an MIS concentration from the University of Minnesota, Minneapolis (1984). He has taught a wide variety of information systems courses over the last 30 years, but currently concentrates in networking courses such as LAN/WAN systems and network administration. His research interests include networking, the job market in computer information systems, and assessment.

Wayne Haga is a professor of computer information systems at Metropolitan State University of Denver. He holds a Ph.D. in applied statistics from the University of Northern Colorado. Over the past 30 years he has taught a wide variety of information systems and quantitative methods courses, including courses in web development, database, and programming. His research interests include project management, simulation, and online delivery of courses. 